\title{
Status of Wildlife Habitats in Ramnagar Forest Division, Terai- Arc Landscape, Uttarakhand, India
}

\author{
Tanveer Ahmed ${ }^{1,2^{*}}$, Harendra Singh Bargali ${ }^{2}$, Neha Verma $^{3}$ and Afifullah Khan ${ }^{1}$ \\ ${ }^{1}$ Department of Wildlife Sciences, Aligarh Muslim University, Aligarh, Uttar Pradesh, India \\ ${ }^{2}$ The Corbett Foundation, Dhikuli, Ramnagar, Nainital, Uttarakhand, India \\ ${ }^{3}$ Ramnagar Forest Division, Ramnagar, Nainital, Uttarakhand, India \\ *Email: tanveerwildlife@gmail.com
}

\begin{abstract}
The Terai-Arc Landscape in the foothills of Himalaya supports a mosaic of wildlife habitats that sustains an amazing biodiversity. The high human pressure coupled with developmental activities, not only degrade wildlife habitats but restrict the dispersal of wild animals particularly in multiple-use managed forest. We determined the status of wildlife habitats in Ramnagar Forest Division classifying Landsat 8 OLI/TIRS image acquired on April 2015. Landsat Aster GDEM data of 17 October 2011 was used to assess slope, aspect and elevation of the study area. Sal forest was the dominant class and it was followed by sal mixed forest, mixed forest, human habitation and barren land. The elevation ranges between $307 \mathrm{~m}$ and $1892 \mathrm{~m}$ amsl with sizable area having gentle slope $\left(5^{0}\right.$ to $\left.10^{\circ}\right)$. Most of the region was south facing. Importance of these habitats for mammals of western Terai-Arc Landscape has been discussed. The current information is expected to serve as baseline information for planning future management strategies and determining changes in wildlife habitats.
\end{abstract}

Keywords: Landuse/landcover, geomorphology, mammals, Terai-Arc Landscape, India

\section{Introduction}

The Terai-Arc Landscape (TAL), covering an area of 30,000 sq. km. spreads over Shivalik hills, Bhabar tract and the Terai plains of India [1]. It runs parallel to the foothills of Himalaya in the states of Uttarakhand, Uttar Pradesh and Bihar in northern part of India. About half (15223 sq. km) of the TAL is forested and is represented by moist Shivalik forest, dry deciduous scrub and grasslands, dry plain sal forest, northern dry mixed deciduous forest, Gangetic moist deciduous forest and plantations [2]. TAL supports a mosaic of wildlife habitats; sal forest, sal mixed, mixed forest, grassland, riverbed, swamp forest, moist riverine forest, dry riverine forest, plantations, scrubland, rivers, bareland and wetlands those sustain an amazing biodiversity representing Himalayan and Gangetic plain affinities [3]. However, these wildlife habitats have high pressure due to high human density ( $>500$ per sq. km) in this landscape [4].

The western part of TAL harbours populations of wild animals belonging to various categories of IUCN Red List of Threatened species, Schedule I of Indian Wildlife (Protection) Act, 1972, and various Appendices of the Convention on International Trade in Endangered Species of Flora and Fauna (CITES). The average wild ungulate density $(35.16 \pm 5.67$ individuals/ sq. $\mathrm{km})$ in western TAL supports tiger (Panthera tigris) and other carnivore species [5]. However, animal populations are distributed in islands of protected areas intermixed with multiple-use managed forests, agriculture land and human habitation. Management of wildlife and their habitats along with rigorous protection and conservation efforts during last couple of decades have revived the population of wild animals [6]. The dispersal of wild animals in search of food and new territories has been facilitated by corridors and habitats within multiple use managed forests. These forests also support healthy populations of herbivores and carnivores in western TAL [5]. Hence, protection and management of multiple use managed forests adjoining protected areas are crucial.

The study area; Ramnagar Forest Division (henceforth RFD) located to the east of Corbett Tiger Reserve (CTR) serves as corridor for the movement of Asian elephant, Tiger and other wild animals from CTR to Nandhaur Wildlife Sanctuary which is contiguous to Nepal in eastern TAL. Also, being 
rich in floral and faunal diversity, it serves as an extended habitat to CTR and supports breeding population of umbrella species like Tiger and its prey. However, anthropogenic pressure due to mushrooming hotels and resorts, low cost housing, development of new roads at the periphery of RFD is causing considerable shrinkage of agriculture land and obstructing animal movement between eastern and western TAL [7].

Remote sensing (RS) coupled with Geographic Information System (GIS) have effectively been used to provide information on forest cover, vegetation types and landuse changes across the globe $[8,9,10$, $11,12,13]$. Studies conducted in adjoining CTR $[14,15,16]$ have been proved useful in creating baseline information necessary for effective management planning, monitoring and change detection. Considering the fact that no such study has been carried out in the RFD which is an important link between eastern and western TAL, the present study was initiated to understand the wildlife habitats, their composition and dynamics. In this paper we present information on proportion of various wildlife habitats along with elevation, slope and aspect in RFD. The current information is expected to fill the gap in knowledge about the RFD, serve as baseline for future research and help in determining changes in wildlife habitats those may occur in future.

\section{Data and Methodology}

\subsection{Study Area}

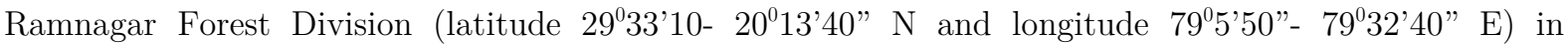
western part of Terai-Arc landscape is located in the state of Uttarakhand, India (Fig. 1). It is contiguous with the Shivalik hills in the north and boarders Gangetic plains in the south. To the west, lie the River Kosi and River Gola to the east. Dabka, Bor, Nihal and Bhakra are other important rivers flowing through this area. Topography of the region is characterized by hilly terrain with coarse soil and boulders in the north and fine alluvium and clay rich swamps with a shallow water table in the south. The area receives an average annual rainfall of $1925 \mathrm{~mm}$ mostly during the southwest monsoon (JuneSeptember).

Vegetation is represented by trees such as Shorea robusta, Anogeissus latifolia, Terminalia alata, Terminalia bellerica, Syzygium cuminii, Lagerstroemia parviflora, Mallotus philippensis, Cassia fistula, Adina cordifolia and Linnea coromandelica. The shrub layer largely consists of Clerodendron viscosum, Murraya koenigii, Adhatoda vasica, Colebrookia oppositifolia and Lantana camara. Nilgai (Boselaphus tragocamelus), Sambar (Rusa unicolor), Chital (Axis axis), Barking deer (Muntiacus muntjak), Himalayan Serow (Capricornis thar), Goral (Naemorhedus goral) and wild boar (Sus scrofa) are the common ungulates in RFD which supports significant population of Tiger, leopard (Panthera pardus) and other co-predators. RFD also supports healthy population of Asian elephant (Elephas maximus).

\subsection{Methodology}

An area of 593 sq. km was considered to delineate the wildlife habitats in RFD. Habitats were assessed using a Landsat 8 Operational Land Imager (OLI)/Thermal Infrared Sensor (TIRS) image between February and December 2016. It involves five main steps 1) Acquiring satellite images 2) reconnaissance survey of the area 3) classification of satellite image 4) ground truthing 5) assessment of classification results (Figure 2).

Landsat 8 scene taken on April 10, 2015 was used to prepare a false colour composite (FCC) using the four bands i.e. band 2 (blue; 0.45-0.51), band 3 (green; 0.53-0.59), band 4 (red; 0.64-0.67) and band 5 (NIR; 0.85-0.88). A subset of the area of interest (AOI) was extracted using vector shape file of the RFD. The subset was classified into 500 classes through unsupervised classification in Erdas 14. These classes were finally merged in various major habitat categories on the basis of ground knowledge, colour, tone, texture and digital number of pixels (Table 1). Post classification of image, accuracy of the map was evaluated by visiting more than 300 different locations. The variation in elevation, slope and aspect was determined through Aster Global Digital Elevation Model (Aster GDEM) acquired on 17 October 2011 available at a $30 \mathrm{~m}$ resolution. 


\section{Results}

RFD supports eleven habitats viz. sal forest, sal mixed forest, mixed forest, teak plantation, scrubland, moist riverine forest, dry riverine forest, barren land, waterbody, agriculture with human habitation and plantation (Table 1). Sal forest is the dominant habitat, encompassing an area of $165.9 \mathrm{sq} . \mathrm{km}(28 \%$ of the total area). Sal mixed forest is the next dominant class (26\% of the total area) and it is followed by mixed forest ( $22 \%$ of the total area). The accuracy of the map was $87 \%$.

The elevation in RFD ranges between 307 and $1892 \mathrm{~m}$ (Fig. 4). High elevation (1200-1892 m) occurs in the northern portion of RFD (Fig 4a) while nearly half of the area falls under the elevation range of $307 \mathrm{~m}-600 \mathrm{~m}$. A small area (1.06\%) falls under the high elevation category of $1500 \mathrm{~m}-1892 \mathrm{~m}$ (Fig. 4b). The slope ranges from flat areas of $0^{\circ}$ to a maximum of $63^{0}$; very steep slopes (Fig. 5a). The areas of high slope occur in northern portion of RFD. Most of the region in RFD has $0^{0}-10^{0}$ slope covering $44.4 \%$ of the area (Fig. 5b). Very few percent of area lies within more than $40^{0}$ slopes $(2.7 \%)$. The distribution of aspect in RFD was proportionate (Fig. 6a). For instance, southern aspect, south-west and south east spread over $17.07 \%, 16.5 \%$, and $13.6 \%$ of area respectively (Fig. 6b).

\section{Discussion}

Habitat supports survival of an animal by fulfilling its basic requirements i.e. food, shelter, cover, water and space. Size of the available habitat is proportional to the richness of wild animals as hypothesized by MacArthur [17] and MacArthur and Wilson [18] supported by many studies on birds [19, 20] and mammals [21].

RFD supported eleven habitats with the domination of sal forest. Our results corroborates the outcomes of Forest Survey of India [2] highlighting the dominancy of Moist Siwalik Sal Forest $10 \mathrm{~km}$ around the Corbett Tiger Reserve. RFD form the eastern continuation of Corbett Tiger Reserve, hence dominancy of sal forest is evident. Sal forest in RFD is dominated by Shorea robusta with occasional occurrence of Terminalia alata and Aegle marmelos and Mallotus philippensis. Such forest is a suitable home for Sambar, Himalayan goral and Barking deer. In Corbett Tiger reserve, Pant et al. [22], reported that sal forest highly suits to the habitat demand of sambar. In Rajaji Tiger Reserve, sal forest was found suitable habitat for goral [23]. In Nepal, Barking deer, Himalayan Goral and Himalayan serow mainly occurred in sal forest [24]. Sal mixed forest which forms the second dominant in RFD is characterized by Shorea robusta along with various other sal associated species like Mallotus philipensis, Anogeissus latifolia, Adina cordifolia, Lagerstroemia parviflora, Terminalia alata etc. In Rajaji Tiger Reserve, sal mixed forest serves as the most suitable habitat for Himalayan goral [9].

Mixed forest in RFD is an assortment of various tree species like Adina cordifolia, Toona ciliata, Mitragyna parviflora, Mallotus philippensis, Terminalia arjuna, Terminalia alata, Aegle marmelos, Shorea robusta, Bahunia recemosa, Ficus benghalensis, Ficus religiosa, Melia azedarach, Lannea coromandelica, Schleichera oleosa, Ziziphus mauritiana, Madhuca indica, Cassia fistula, Diospyros melanoxylon, Crateva religosa, Bombax ceiba etc. in different proportion. Mixed forest serves as suitable habitat for Himalayan goral in Rajaji Tiger Reserve [9, 23] and Tiger and sambar in Panna Tiger Reserve [25]. Mondal et al. [26] highlighted that the presence of leopards increased with increasing area of Ziziphus mixed forest patches in Sariska Tiger Reserve.

Human habitation which constituted a considerable part of RFD is generally avoided by various wild animals. Barking deer, Himalayan goral and Himalayan serow maintain a distance of more than $250 \mathrm{~m}$, $750 \mathrm{~m}$ and $1000 \mathrm{~m}$ respectively from human habitation [24]. However, some other species show close affinity with human habitation. For example, scrubland close and areas close to human habitation supports occurrence of Jungle cat (Felis chaus) [27, 28, 29]. Maharjan et al. [30] highlighted distance from settlement area play a significant role in predicting the distribution of common leopard in the Shivpuri Nagarjun National Park, Nepal.

Riverine forest in RFD is either moist riverine or dry riverine. The former is largely dominated by Syzygium cuminii and Trewia nudiflora while latter by Holoptelea integrifolia, Dalbergia sissoo and Accacia catechu. Riverine forest along with available water sources might serve as suitable habitat for small Indian civet (Viverricula indica). Gupta [28] reported the affinity of small Indian civet to dense canopy cover and available water sources in a dry semi-arid forest of north-west India. Teak plantation 
provide habitat to Indian porcupine (Hystrix indica), black-naped hare (Lepus nigricollis), Asian elephant and wild boar [31].

Most area in RFD is under 900 m elevation. In Panna Tiger Reserve Tiger and sambar occurred at an elevation ranging between 400-500 and 800-900 m elevation while Chital generally occurred below 400m [25]. High elevation areas are generally present in northern part of RFD. In Corbett Tiger Reserve, Pant et al. [22] reported an elevation between $800-1180 \mathrm{~m}$ to be highly suitable for sambar. In Prek Chu river catchment of the Khangchendzonga Biosphere Reserve, the occupancy of Leopard cat (Prionailurus bengalensis) is negatively influenced by elevation [32].

Aspect also plays an important role in governing the distribution of species. Barking deer and sambar diliered in their choice of aspects for bed sites; barking deer chose west-facing areas, while sambar chose east-facing locations [33]. Ilyas [34] reported barking deer mostly on north-west aspect during pre and post monsoon. Goral used west and north-east aspect during pre and post monsoon respectively [34].

The various habitats in RFD are important to various mammals categorized under IUCN Red List of Threatened Species and Schedule I of Indian Wildlife (Protection) Act-1972. Dependency for fuel wood, fodder and small amount of timber along with proliferation of hotels and resorts along the western boundary of RFD might be harmful to the wild animals. The current information thus serves as the baseline to determine change in the habitats of wild animals.

Acknowledgments. The present study was a part of the biodiversity assessment of Ramnagar Forest Division financed by The Corbett Foundation. The authors are grateful to Mr. Dilip Khatau, Chairman, The Corbett Foundation for his valuable contribution to the project. Authors also express sense of gratitude to Mr. Kedar Gore, Director, the Corbett Foundation for supporting this study. Special thanks to Miss Aimon Bushra and Anam Ahsan from Indian Institute of Remote Sensing for providing the inputs required for the study. We also thank Mr. Mohd. Yaseen and Mr. Kubair Mehra and staff of Ramnagar Forest Division for helping us in conducting field surveys.

\section{References}

1. W.A. Rodgers and H.S. Panwar, Planning a Wildlife Protected Area Network in India". II Volume. Project FO: IND/82/003. FAO, Dehradun, India. 1988.

2. Forest Survey of India, Status, density and change in forest cover of Tiger Reserves in respect of 'Shivalik Gangetic plain landscape. Ministry of Environment \& Forests, Government of India Dehradun, India, 2014.

3. P.K. Mathur and N. Midha, Mapping of National Parks and Wildife Sanctuaries, Dudhwa Tiger Reserve. WIINNRMS-MoEF Project, Final Technical Report, Wildlife Institute of India, Dehradun, India. 2008.

4. A.J.T. Johnsingh, Q. Qureshi, S.P. Goyal, G.S. Rawat, K. Ramesh, A. David, K. Rajapandian and S. Prasad, Conservation Status of Tiger and Associated Species in the Terai Arc Landscape, India. RR-04/001, Wildlife Institute of India, Dehradun, India, 2004.

5. A. Harihar, B. Pandav and D.C. MacMillan, "Identifying realistic recovery targets and conservation actions for tigers in a human-dominated landscape using spatially explicit densities of wild prey and their determinants," Diversity and Distributions, vol. 20, no. 5, pp. 1-12, 2014.

6. Y.V. Jhala, Q. Qureshi and R. Gopal, The status of tigers in India 2014. National Tiger Conservation Authority, New Delhi \& The Wildlife Institute of India, Dehradun, India, 2015.

7. J. Mazoomdaar, "Corbett - now on sale," Tehelka Magazine, vol. 9, no. 19, 2012.

8. N.C. Gautam and G. CH. Chennaiah, "Land-use and land-cover mapping and change detection in Tripura using satellite LANDSAT data," International Journal of Remote Sensing, vol.6, no. 3, pp. 517-528, 1985.

9. S.P.S. Kushwaha and P.S. Roy, "Geospatial technology for wildlife habitat evaluation," Tropical Ecology, vol. 43, no. 1, pp. 137-150, 2002.

10. K. Chakraborty, "Vegetation change detection in Barak Basin.," Current science, vol. 96, no. 9, pp. 1236-1242, 2009.

11. M.E. Hereher, A.M. Al-Shammari and S.E. Abd Allah, "Land Cover classification of Hail-Saudi Arabia using Remote Sensing," International Journal of Geosciences, vol. 3, pp. 349-356, 2012.

12. B. Habib, S.P.S. Kushwaha, A. Quadri and A. Khan, "Application of remote sensing and geographic information system in wildlife habitat modelling," Journal of the Bombay Natural History Society, vol. 103(2/3), pp. 366, 
2006.

13. A. Khan and A.K. Thakur, Mapping of National Parks and Wildlife Sanctuaries, Corbett Tiger Reserve, Uttarakhand. WII- NNRMS MoEF Project Final Technical Report, Wildlife Institute of India, Dehradun, India. 2008.

14. S.P.S. Kushwaha, A. Khan, B. Habib, A. Quadri and A. Singh, "Evaluation of sambar and muntjak habitats using geostatistical modelling," Current Science, vol. 86(10), pp. 1390 - 1400, 2004.

15. A. Khan, "Elephant conservation Unit-Linking two elephant populations in North-Western India," in $A$ week with elephants," Oxford University Press, 1996, pp 162-176.

16. S.P.S Kushwaha, A. Quadri, A. Singh and A. Khan, Habitat preference assessment on the tiger and its prey ungulates in the Corbett Tiger Reserve. Fauna of Corbett Tiger Reserve: (Uttarakhand. A Publication of Zoological Survey of India, Govt. of India, 2008.

17. R.H. MacArthur, "Pattern of species diversity,"Biological Review, vol. 40, pp. 510-533, 1965.

18. R.H. MacArthur and E.O. Wilson, The theory of island biogeography. Princeton University Press, Princeton, 1967.

19. M.A. MacDonald and J.B. Kirkpatrick, "Explaining bird species composition and richness in eucalyptdominated remnants in subhumid Tasmania, "Journal of Biogeography, vol. 30, pp. 1415-1426, 2003.

20. W. Kang, E.S. Minor, C. Park and D. Lee, "Effects of habitat structure, human disturbance, and habitat connectivity on urban forest bird communities," Urban Ecosystem, vol. 18, no. 3, pp. 857-870, 2015.

21. A.G. Chiarello, "Effects of fragmentation of the Atlantic forest on mammal communities in south-eastern Brazil,"Biological Conservation, vol. 89, pp. 71-82, 1999.

22. A. Pant, S.A. Chavan, P.S. Royand K.K. Das, "Habitat analysis for Sambar in Corbett National Park using Remote Sensing and GIS," Journal of the Indian Society of Remote Sensing, vol. 27, no. 3, pp. 133-139, 1999.

23. S.P.S. Kushwaha, S. Munkhtuya and P.S. Roy, "Mountain goat habitat evaluation in Rajaji National Park using Remote Sensing and GIS," Journal of the Indian Society of Remote Sensing, vol. 28, pp. 293-303, 2001.

24. P.K. Paudel, M. Hais and P. Kindlmann, "Habitat suitability model of mountain ungulates: Identifying potential areas of conservation," Zoological studies, vol. 54, pp. 1-16, 2015.

25. R.K. Prajapati, S. Triptathi and R.M. Mishra, "Habitat modeling for Tiger (Penthra Tigris) using geo-spatial Technology of Panna Tiger Reserve (M.P.) India," International Journal of Scientific Research in Environmental Sciences, vol. 2, no. 8, pp. 269-288, 2014.

26. K. Mondal and K. Sankar and Q. Qureshi, "Factors influencing the distribution of leopard in a semiarid landscape of Western India," Acta Theriologica vol. 58, pp. 179-187. 2012.

27. S. Mukherjee, Habitat use in sympatric small carnivores in Sariska Tiger Reserve, Rajasthan, Western India. PhD Thesis, University of Saurashtra, Biosciences Department, India, 1998.

28. S. Gupta, Ecology of medium and small sized carnivores in Sariska Tiger Reserve, Rajasthan, India. PhD Thesis, Saurashtra University, 2011.

29. R. Kalle, T. Ramesh, Q. Qureshi and K. Sankar, "Predicting the Distribution Pattern of Small Carnivores in Response to Environmental Factors in the Western Ghats," PLoS ONE vol. 8 no. 11: e79295. doi:10.1371/journal.pone.0079295, 2013.

30. B. Maharjan, Shahnawaz, T.B. Thapa, P.M. Shrestha, "Geo-spatial Analysis of Habitat Suitability for Common Leopard (Panthera pardus Linnaeus, 1758) in Shivapuri Nagarjun National Park, Nepal," Environment and Ecology Research, vol. 5, no. 2, 117-128. 2017.

31. E. O. Jayson, "Habitat preference of five herbivores in the Chimmony Wildlife Sanctuary. Indian Forester, vol. 125, no. 10, 975-985, 1999.

32. T. Bashir, T. Bhattacharya, K. Poudyal, S. Sathyakumar and Q. Qureshi, "Integrating aspects of ecology and predictive modelling: Implications for the conservation of the leopard cat (Prionailurus bengalensis) in the Eastern Himalaya," Acta Theriologica, vol.59, no. 1, pp. 35-47, 2013.

33. J.F. Brodie and W.Y. Brockelman, "Bed site selection of red muntjac (Muntiacus muntjak) and Sambar (Rusa unicolor) in a tropical seasonal forest,"Ecological Research vol. 24, pp. 1251-1256, 2009.

34. O. Ilyas, "Status and conservation of ungulates in the Kumaon Himalayas with special reference to aspect of ecology of barking deer (Muntiacus muntjak) and Goral (Nemoehaedus goral). PhD. Thesis, Aligarh Muslim University, Aligarh, 2001. 
Table 1. Proportion of area under various habitat types in Ramnagar Forest Division, Uttarakhand, India

\begin{tabular}{|c|c|c|c|}
\hline Habitats & Description & $\begin{array}{l}\text { Area } \\
\text { (sq. km) }\end{array}$ & $\%$ \\
\hline $\begin{array}{l}\text { Human settlement } \\
\text { with Agriculture }\end{array}$ & Human settlements interspersed in Agricultural fields. & 56.8 & 9.6 \\
\hline Barren land & Area devoid of any vegetation such as dry river beds & 29.7 & 5.0 \\
\hline Dry riverine forest & $\begin{array}{l}\text { Mixed patches of either Holoptelea integrifolia and Dalbergia sissoo or } \\
\text { homogenous patches of Acacia catechu on dry sandy bars along the rivers } \\
\text { and streams. }\end{array}$ & 9.4 & 1.6 \\
\hline Mixed forest & $\begin{array}{l}\text { Forest stands comprised of different tree species without anyone species } \\
\text { being numerically dominant. }\end{array}$ & 128.0 & 21.6 \\
\hline Moist riverine forest & $\begin{array}{l}\text { Forests along the wet river courses dominated by Syzygium cumminii and } \\
\text { Trewia nudiflora }\end{array}$ & 9.0 & 1.5 \\
\hline Plantation & $\begin{array}{l}\text { Orchards in the vicinity of villages and plantations either raised by } \\
\text { villagers or Forest Department. }\end{array}$ & 1.7 & 0.3 \\
\hline Sal forest & $\begin{array}{l}\text { Forest stands where Shorea robusta is occurring as numerically dominant } \\
\text { species. }\end{array}$ & 165.9 & 28.0 \\
\hline Sal mixed forest & $\begin{array}{l}\text { Shorea robusta along with its other associate species like Mallotus } \\
\text { philippensis, Anogeissus latifolia, Legerstroemia parviflora, Terminalia } \\
\text { alata. }\end{array}$ & 154.4 & 26.0 \\
\hline Scrubland & Areas of shrubby vegetation with sparse trees. & 16.3 & 2.7 \\
\hline Teak plantation & Homogenous plantation of Tectona grandis & 19.7 & 3.3 \\
\hline Water body & Rivers, streams, ponds and lakes. & 2.6 & 0.4 \\
\hline
\end{tabular}

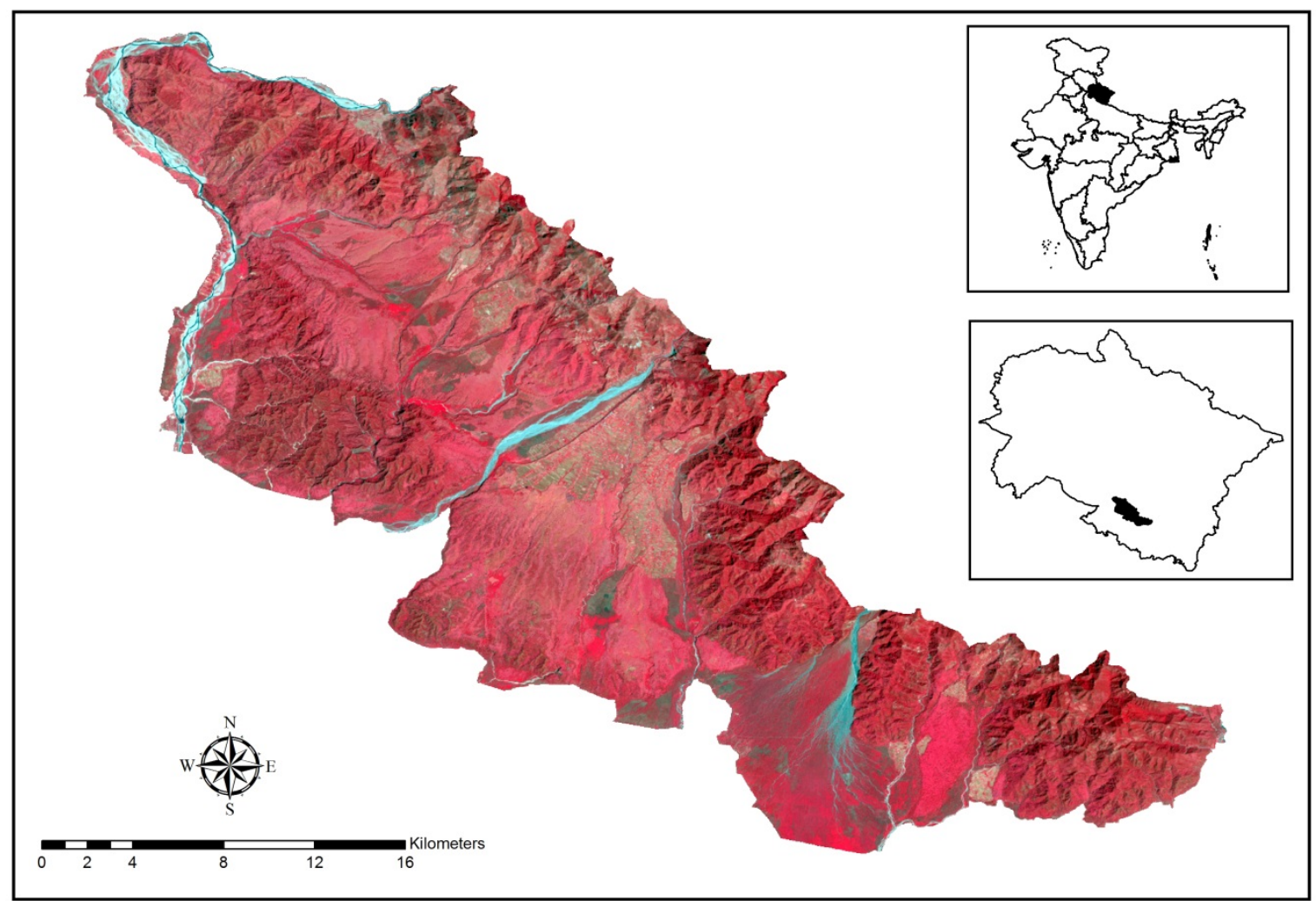

Figure 1. Location of Ramnagar Forest Division, Uttarakhand, India 


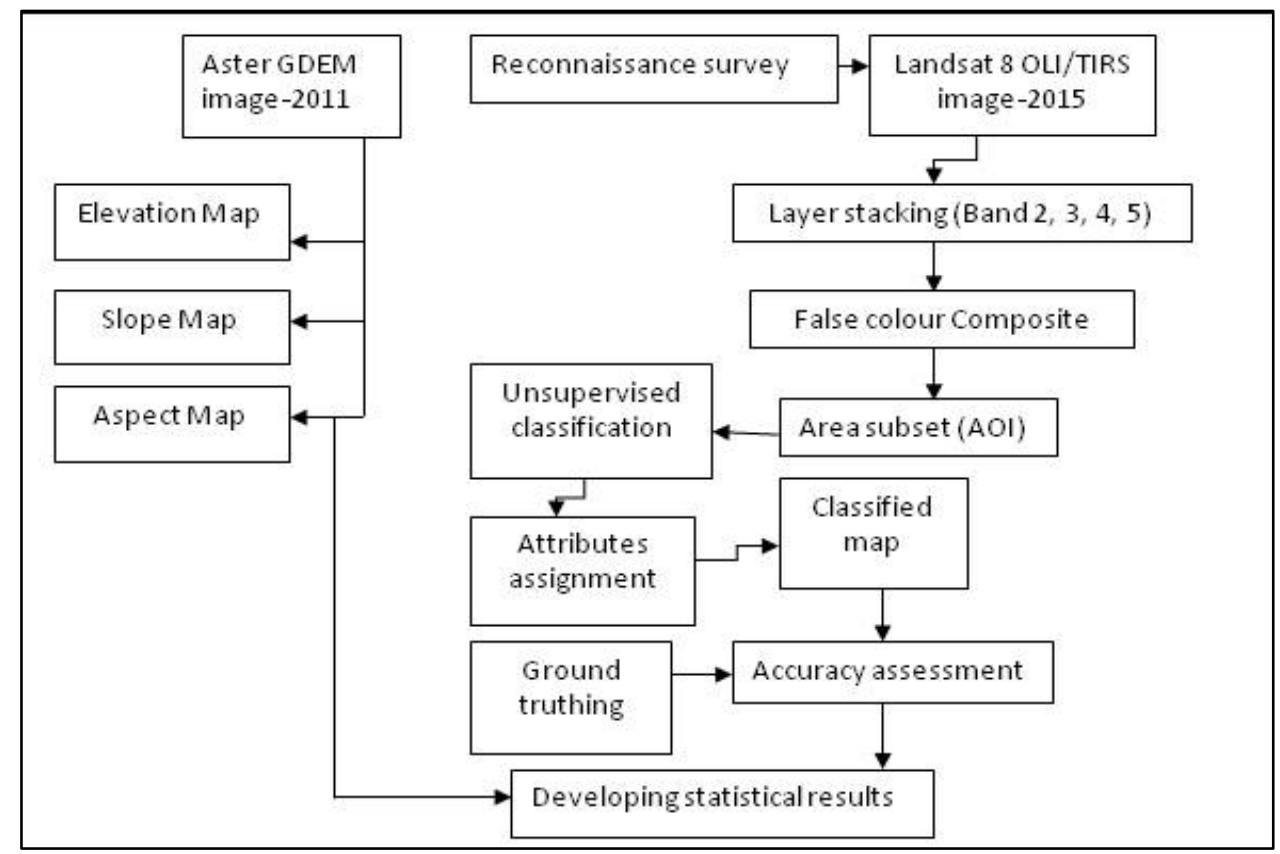

Figure 2. Flowchart of the methodology used to assess wildlife habitats in Ramnagar Forest Division, Uttarakhand, India

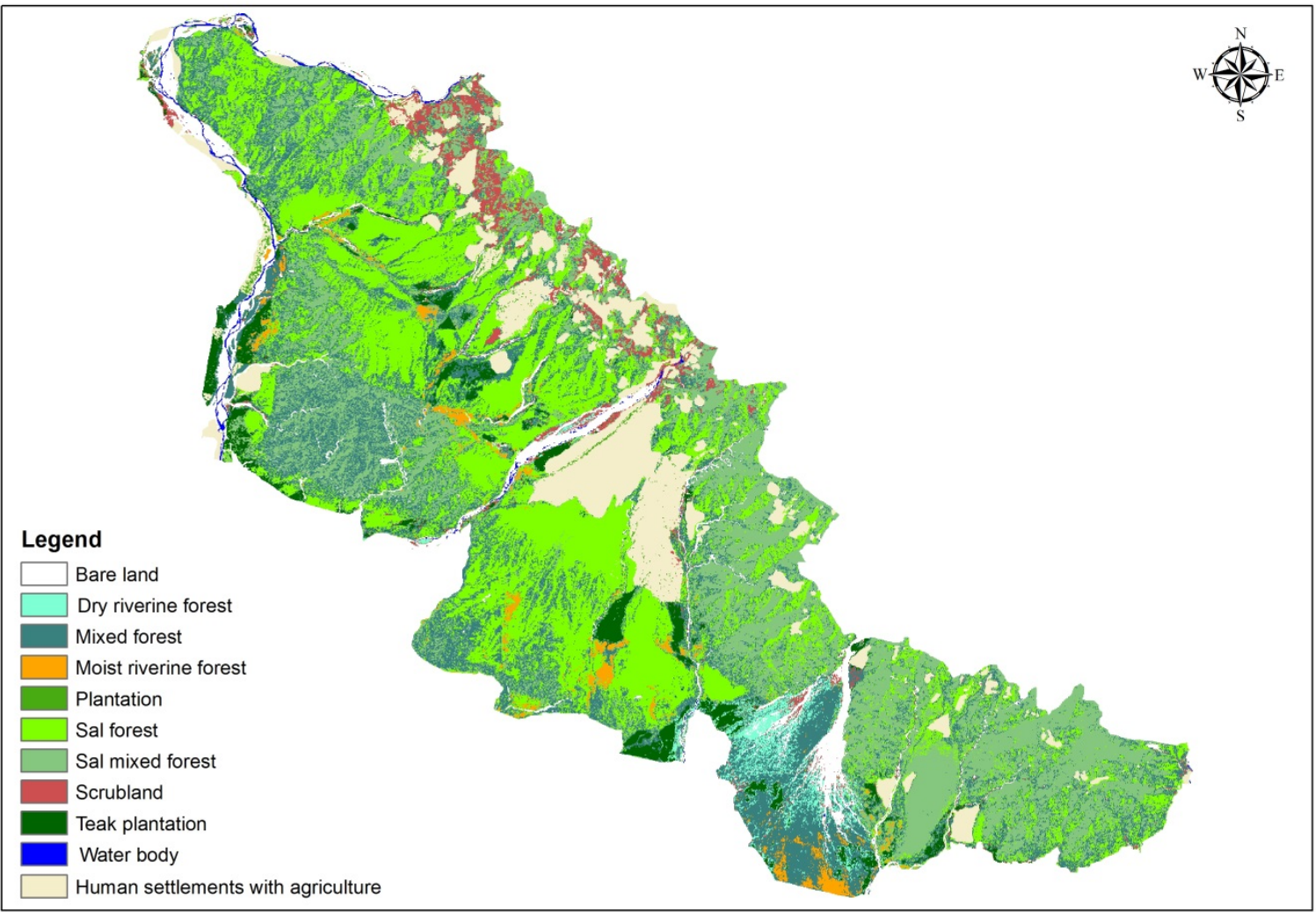

Figure 3. Spatial distribution of various wildlife habitats in Ramnagar Forest Division, Uttarakhand, India 


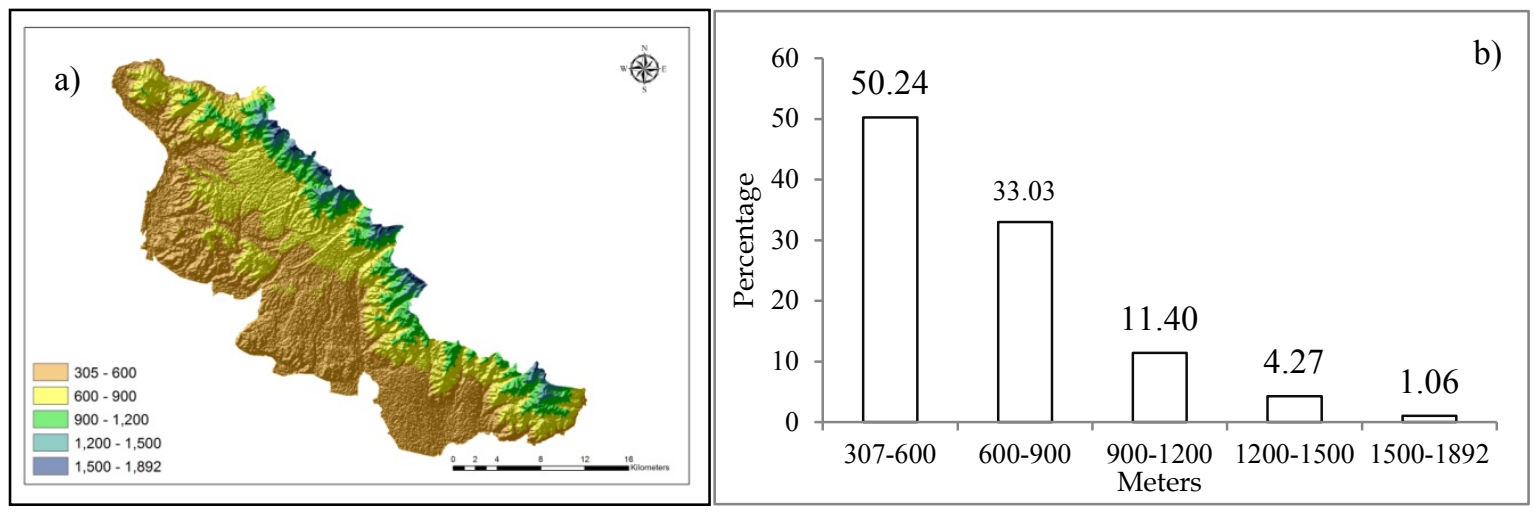

Figure 4. Spatial distribution and proportion area under various elevation categories in Ramnagar Forest Division, Uttarakhand, India
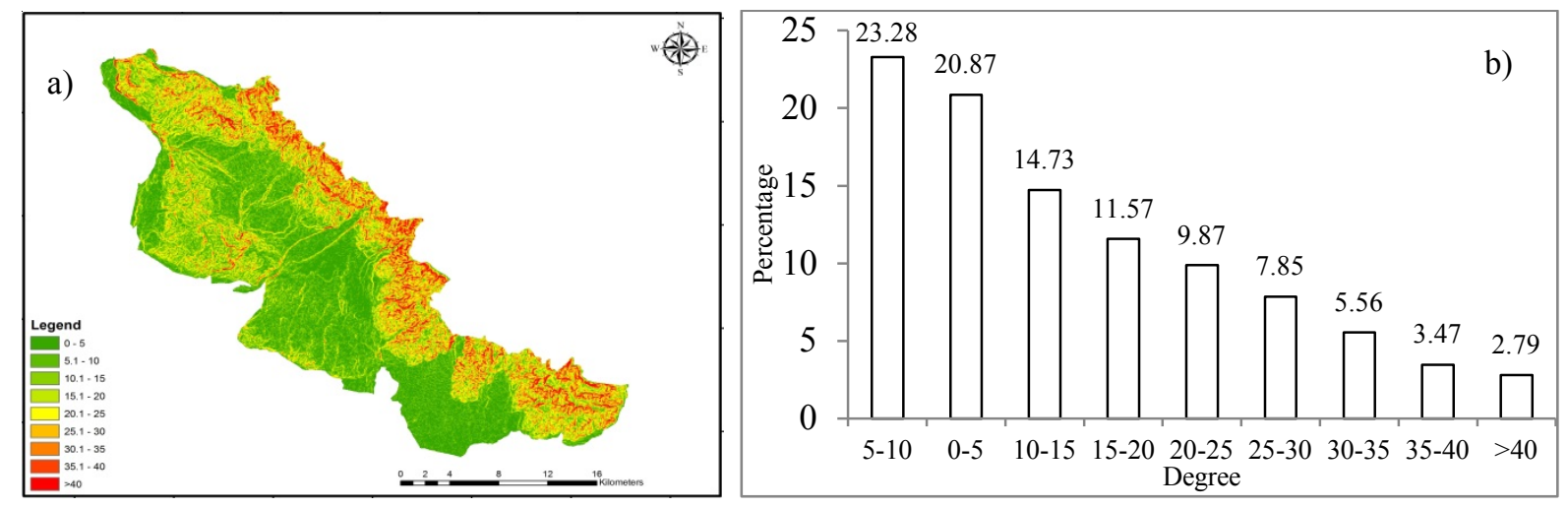

Figure 5 Spatial distribution and proportion of area under various slope categories in Ramnagar Forest Division, Uttarakhand, India
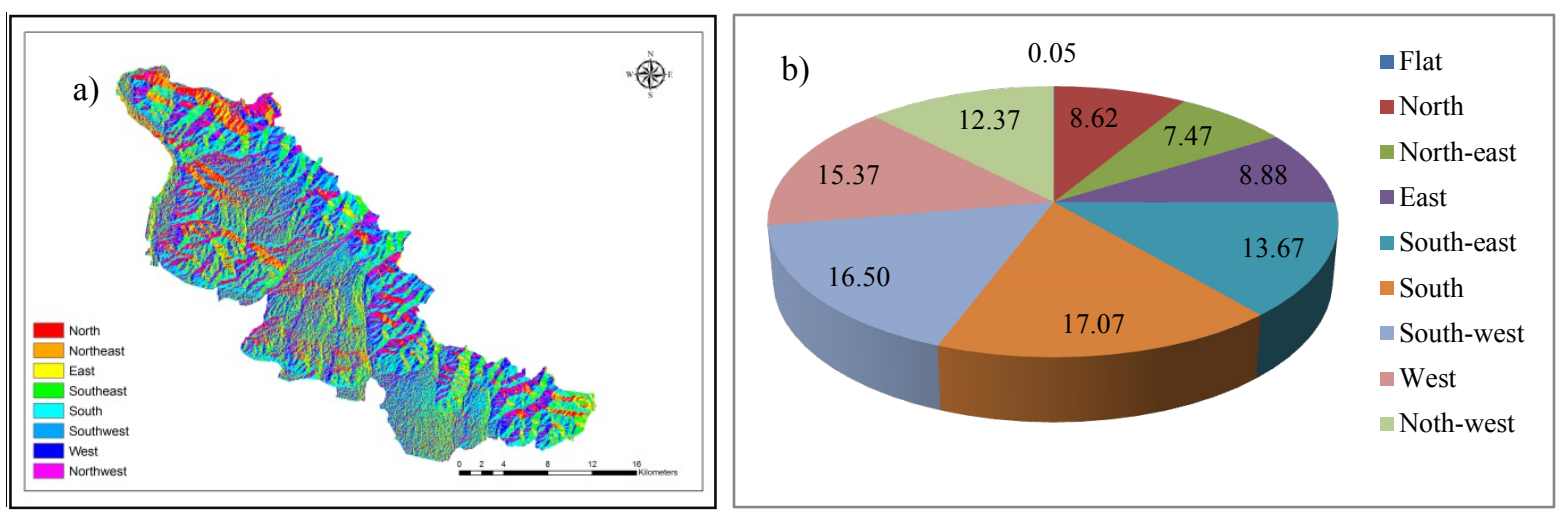

Figure 6. Spatial distribution and Proportion of area under various aspects in Ramnagar Forest Division, Uttarakhand, India 